\title{
High yields of sugars via the non-enzymatic hydrolysis of cellulose
}

\author{
V. Berberi ${ }^{1}$, F. Turcotte ${ }^{1}$, G. Lantagne ${ }^{2}$, M. Chornet $^{1,3}$ \\ \& J.-M. Lavoie ${ }^{1}$ \\ ${ }^{1}$ Département de Génie Chimique, Université de Sherbrooke, Canada \\ ${ }^{2}$ Institut de recherche d'Hydro-Québec (IREQ), Canada \\ ${ }^{3}$ CRB Innovations Inc., Canada
}

\begin{abstract}
Given the cost of cellulosics (quasi-homogeneous residual feeds range in North America, between US\$60-80/tonne, dry basis, FOB conversion plant) their fractionation and subsequent use of the intermediate fractions is a strategy that makes economic sense. Furthermore, it permits the isolation of cellulose with low contents of lignin and hemicellulose. Once the cellulose is isolated, its use as a chemically pulped fibre and the conversion of the fines into glucose becomes possible. The authors' group has been working on the chemical depolymerisation of the cellulose (both the fines and the fibres as well) using highly ionic solutions. The method implies recovery of both anions and cations by state of the art technologies. This paper presents the fractionation + ionic decrystallization and depolymerisation approach, provides and discusses its energy balance and compares it with the enzymatic route for hydrolysis in applications to $<40 \mathrm{MML}$ Biofuels/y plants which correspond to $<100000 \mathrm{t} / \mathrm{y}$ of input lignocellulosics, dry basis.

Keywords: cellulose, hydrolysis, depolymerization, electrodialysis, biofuels.
\end{abstract}

\section{Introduction}

In North America, residual forest and agricultural biomass cost actually US\$60 80 per dry tonne FOB. Such biomass could be considered chemically as quasihomogeneous since although it may contain the same macromolecules and metabolites (extractives, hemicelluloses, cellulose and lignin), the concentration of each may vary as a function of season, due to weathering and other reasons. 
Energy crops or "non-conventional" cultures could also be included in this category since they usually are a "mixture" of different tissues although at this point, this biomass is slightly more expensive, reaching close to US $\$ 100$ per dry tonne FOB. Conversion of biomass to biofuels and "green chemicals" can be achieved through two general approaches which are categorized as "thermo" or "bio" pathways [1,2]. Conversion of lignocellulosic biomass could also be achieved through a combination of both [3].

The "bio" approach relies on biological conversion of biomass at one point or the other during the process. This approach is somehow at this point limited by three technological challenges which are 1) the isolation of the cellulose and 2 ) its hydrolysis to glucose. The last technological aspect (3) that has to be considered is the fermentation of cellulosic sugars which may require additional nutriment to be efficient. The first challenge has been overcome for years by the pulp and paper industry although there is actually a need to develop new techniques leading to the production of pulp which will overall lead to cheaper and less water- and chemicals-consuming processes. Many approaches have been considered to isolate cellulose among which different steam treatments and solvent-related process have been thoroughly investigated [4]. Although isolation of cellulose from the biomass matrix could be performed under different conditions, another key to the economic viability of a biorefinery process is the isolation and utilisation of the other macromolecular fractions of the biomass as lignin and hemicelluloses. Although in many cases, the preliminary conversion process will use thermal and chemical energy, some reports have been made in literature on biological pre-treatment to isolate cellulose [4].

The second key technological challenge that needs to be overcome is the hydrolysis of glucose which is a crucial aspect of the production of cellulosic ethanol. Cellulose is composed of a crystalline and an amorphous phase. In most cases, the amorphous phase is the more vulnerable to hydrolysis, chemical and biological as well. The latter usually relies on a mixture of 3 types of enzymes, endoglucanases, exoglucanases (cellobiohydrolases), and $\beta$-glucosidases [5]. The major problems delaying commercialisation of enzyme-based technologies are related on the cost of enzymes. Cellulose is composed of glucose units linked together by acetal bonds and the latter are weakened by an acid catalyst. Therefore, utilisation of acid should in theory be an option, although the major problem in this case is the penetration of the acid in the cellulose crystalline and amorphous structure. Such a concept is not applicable since the cellulose macromolecules are oriented so that the polar functional groups are all linked together via hydrogen bonding making the outside section of cellulose highly hydrophobic. Penetration of water would ease the conversion of cellulose to glucose since it would expose the acetal bonds to any type of Lewis acid. Specific compounds can be used to swell cellulose which means that the swelling molecules can "move" between the microfibrils, reach the cellulosic chains and break its hydrogen bonded structure making a hydrogel. Cellulose is therefore less shelled against an attack since the acetal groups are exposed. The compounds that usually allow such specific interactions are usually ionic. This brings the issue of removing them before fermentation of the cellulosic sugars to 
avoid inhibition. Another key aspect is to efficiently remove and recover the ions from the mixture.

This paper will discuss the conversion of residual quasi-homogeneous biomass to ethanol. Cellulose has been isolated from the lignocellulosic matrix using the Feedstock Impregnation Rapid and Sequential Steam Treatment (FIRSST) process. The cellulose-rich pulp produced from this process is then hydrolysed to glucose using a non-enzymatic approach involving ionic aqueous solutions. The broth is then purified using a sequential approach with one of the steps being electrodialysis and the remaining sugars fermented to ethanol using industrial grade yeasts. The energy and mass balance of the whole process will be evaluated to see where such a process could be positioned in comparison to other biological techniques leading to the production of cellulosic ethanol.

\section{Experimental work}

\subsection{Feedstock impregnation rapid and sequential steam treatment}

Two-step FIRSST process. The scheme of the two-step FIRSST process is depicted in fig. 1 below. After extraction of the secondary metabolites, the biomass was impregnated with water without any catalyst and was then pressed at $6.8 \mathrm{~atm}$ (100 psi) to remove the excess water and leave a saturated fiber. After pressing, the biomass is transferred into the 4.5 litres steam gun where about $200 \mathrm{~g}$ (dry basis) of chips were cooked at temperatures from 190 to $220^{\circ} \mathrm{C}$ for 2 5 minutes. Delignification was performed on the pulp obtained from the first steam treatment using a solution of $\mathrm{NaOH}(2-10 \%$ wt of the lignocellulosic material). The wet fibrous solids filtered (as per fig. 1) were then washed again with water 5 times using a water/biomass weight ratio of $5 / 1$. The wet biomass was then impregnated with the alkali solution at $6.8 \mathrm{~atm}$ (100 psi) for 5 minutes.

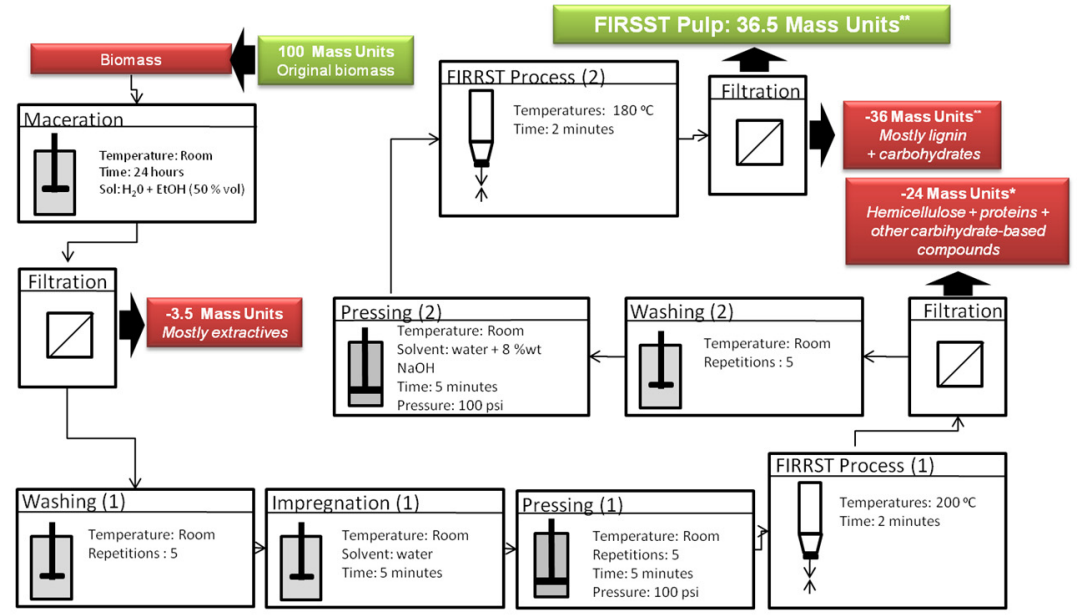

Figure 1: Two steps FIRSST process. 
Delignification was performed at a cooking temperature in the $170-190^{\circ} \mathrm{C}$ range for 2-5 minutes with concentration of $\mathrm{NaOH}$ ranging from 2 to $10 \%$ wt.

\subsubsection{Analysis of the fibres}

The testing methods used to evaluate the fibres produced both using FIRSST pulp and kraft pulp (in terms of comparison) is presented in table 1 below.

Table 1: Identification of the test and the standard techniques used for characterization of both FIRSST and kraft pulp.

\begin{tabular}{cc}
\hline Test & Standard technique identification \\
\hline Freeness Determination & ATPPC C.1 \\
Laboratory Screening of Pulp (Pulmac- & ATPPC C.12 \\
Type Instrument) & \\
Fibre classification (Bauer-McNett) & ATPPC C.5U \\
Fibre Length by Automated Optical & ATPPC B.4P \\
Analyzer Using Polarized Light & \\
Forming Handsheets for Physical Tests & ATPPC C.4 \\
with Pulp & \\
Forming Handsheets for Optical Tests & ATPPC C.5 \\
with Pulp (British Sheet Machine & \\
Method) & \\
Grammage & ATPPC D.3 \\
Brightness & ATPPC E.1 \\
ATPPC E.5 \\
Colour Measurement with a & \\
Diffuse/Zero Geometry Tristimulus & \\
Reflectometer & ATPPC E. 2 \\
Opacity & ATPPC D.4 \\
Thickness and Apparent Density & ATPPC D.9 \\
Internal Tear Resistance & ATPPC D.8 \\
Bursting Strength & ATPPC D.34 \\
Length of rupture & ATPPC D.34 \\
TEA &
\end{tabular}

\subsection{Hydrolysis of the cellulose}

The method used for cellulose hydrolysis is described in the patent \#80685-2 [8]. This method includes an acid pretreatment followed by addition of a source of hydroxide ions. The mixture is then heated to obtain a glucose-rich solution, which is filtered before glucose purification.

The hydrolysis yield is calculated by comparison with the ASTM method No E1758-01R07 [9]. Glucose concentration of the filtrate was measured by HPLC, using an Agilent Chromatograph equipped with an RoA-Organic acid (8\%) column (Phenomenex) and a refractive index detector. The column was eluted with $5 \mathrm{mM}$ sulphuric acid at a flow rate of $0.6 \mathrm{ml} \mathrm{min}^{-1}$ and maintained at $60^{\circ} \mathrm{C}$. The injection volume was $30 \mu \mathrm{l}$. Sulphate concentration was measured by a colorimetric method [10] and ammonium or sodium concentration, by IC. The 
apparatus used was a Dionex ICS-3000 ion chromatograph loaded with an IonPac CS12A (2x250mm) and detection was made with electric conductivity.

Three identical cellulosic hydrolyses were performed with $46 \mathrm{~g}$ of wet cellulose (64\% humidity) each. These tests were done in $2 \mathrm{~L}$ erlenmeyer and hydrolysed in an autoclave. The solution was filtered in a Buchner with Glass fiber Fisher Brand filter. The three filtrates were then mixed for the purification step which, in these tests, was made by using electrodialysis only.

\subsection{Purification of the cellulosic hydrolysate}

A $3 \mathrm{~L}$ mixture of the hydrolysis broth (composed of $\sim 300 \mathrm{~g} / \mathrm{L}$ sodium sulphate, $\sim 300 \mathrm{~g} / \mathrm{L}$ sulphuric acid and between 10-20 g/L glucose) was purified using an electrodialysis system.

Testing was done at the Energy technology Laboratory (LTE) in Shawinigan, QC. The electrodialysis system used was a CS-O batch system from Asahi Glass Co. The cathode and the anode were of iridium oxide and 4 membranes pairs of $180 \mathrm{~cm}^{2}$ each were used. The experimental conditions were: $30^{\circ} \mathrm{C}, 150-200 \mathrm{~L} / \mathrm{h}$ and $20 \mathrm{~A}$ fixed $\left(\mathrm{i}=111 \mathrm{~mA} / \mathrm{cm}^{2}\right)$. The $\mathrm{pH}$, temperature, conductivity, voltage and intensity were measure automatically at time intervals. Each volume of the three compartments was also measured.

\subsection{Fermentation of cellulosic sugars}

Inocula were prepared using a medium containing $0.07 \% \mathrm{w} / \mathrm{w}$ gluco-amylase, $16 \mathrm{mM}$ ammonium sulphate, $0.01 \mathrm{~g} / \mathrm{L}$ Lactrol, $20 \mathrm{~g} / 1$ yeast (Ethanol Red, Fermentis), $60 \mathrm{ml}$ corn mash (32\% solids) and $40 \mathrm{ml}$ water was used. The medium was incubated in an Erlenmeyer flask at $32^{\circ} \mathrm{C}, 150$ RPM for 4 hours.

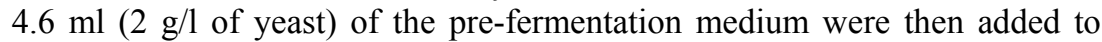
$200 \mathrm{ml}$ of the purified lignocellulosic sugars. $8 \mathrm{mM}$ ammonium sulphate and $0.01 \mathrm{~g} / 1 \mathrm{Lactrol}$ were also added to the fermentation medium. The corn mash used in the pre-fermentation medium provided the necessary trace nutriments. The medium was incubated in $250 \mathrm{ml}$ Erlenmeyer flasks coupled with a fermentation lock at $34.5^{\circ} \mathrm{C}$ and 150 RPM during 44 hours.

Monitoring of the fermentation was made by HPLC, using an Agilent Chromatograph equipped with a RoA-Organic acid (8\%) column (Phenomenex) and a refractive index detector.

\section{Results and discussion}

\subsection{Feedstock impregnation rapid and sequential steam treatment}

The FIRSST process was shown effective for the isolation of the macromolecular structures from different types of lignocellulosic biomass including hardwood (willow), softwood (balsam and fir) and energy crops (hemp and triticale). Production of pulp via the FIRSST process was of $30 \% \mathrm{wt}$ (dry mass) for willow [6], 40\%wt for softwoods [7], 37\%wt for hemp and 34\%wt for triticale. Pulp produce contained about $3-6 \%$ of lignin and the residual fibre was 
mostly composed of $\mathrm{C}_{6}$ sugars. Evaluation of the fibres was made both on chemical and mechanical aspects to verify how the severity of the combined steam treatments could be comparable to a classical kraft pulping process. Comparative results are shown in table 2 below.

Table 2: $\quad$ Mechanical properties of FIRSST pulp and kraft pulp for a species of hardwood (Salix viminalis) and a mixed species of softwood (Abies balsamea and Picea mariana).

\begin{tabular}{|c|c|c|c|c|}
\hline Test & H-FIRSST & H-Kraft & S-FIRSST & S-Kraft \\
\hline $\begin{array}{l}\text { ATPPC C.1 } \\
\pm 1 \mathrm{~mL}\end{array}$ & 409 & 454 & 664 & 721 \\
\hline $\begin{array}{c}\text { ATPPC C. } 12 \\
\quad \pm 0.01 \%\end{array}$ & 12.7 & 0.16 & 5.58 & 0.11 \\
\hline $\begin{array}{l}\text { ATPPC B.4P } \\
\pm 0.01 \mathrm{~mm}\end{array}$ & 0.39 & 0.41 & 2.08 & 2.56 \\
\hline $\begin{array}{l}\text { ATPPC D.3 } \\
\pm 0.1 \mathrm{~g} / \mathrm{m}^{2}\end{array}$ & 60.9 & 60.1 & 59.6 & 61.0 \\
\hline $\begin{array}{c}\text { ATPPC E.1 } \\
\pm 0.1 \%\end{array}$ & 24.7 & 33.3 & 24.8 & 27.6 \\
\hline \multicolumn{5}{|l|}{ ATPPC E.5 } \\
\hline $\mathrm{L}^{*} \pm 0.01$ & 64.22 & 71.45 & 67.26 & 69.36 \\
\hline $\mathrm{a}^{*} \pm 0.01$ & 2.82 & 2.18 & 4.41 & 4.12 \\
\hline $\mathrm{b}^{*} \pm 0.01$ & 13.26 & 12.42 & 18.31 & 17.43 \\
\hline $\begin{array}{c}\text { ATPPC E.2 } \\
\pm 0.1 \%\end{array}$ & 99.6 & 99.5 & 98.5 & 99.3 \\
\hline $\begin{array}{l}\text { ATPPC D.4 } \\
\pm 0.01 \mathrm{~cm}^{3} / \mathrm{g}\end{array}$ & 2.17 & 1.79 & 2.24 & 2.36 \\
\hline $\begin{array}{c}\text { ATPPC D.9 } \\
\pm 0.01 \mathrm{mN}^{*} \mathrm{~m}^{2} / \mathrm{g}\end{array}$ & 4.09 & 3.14 & 8.04 & 25.9 \\
\hline $\begin{array}{c}\text { ATPPC D.8 } \\
\pm 0.01 \mathrm{kPa}^{*} \mathrm{~m}^{2} / \mathrm{g}\end{array}$ & 1.35 & 1.56 & 3.05 & 2.28 \\
\hline $\begin{array}{l}\text { ATPPC D.34 } \\
\pm 0.01 \mathrm{~km}\end{array}$ & 2.78 & 4.24 & 5.03 & 3.87 \\
\hline $\begin{array}{l}\text { ATPPC D.34 } \\
\pm 0.1 \mathrm{~J} / \mathrm{m}^{2}\end{array}$ & 15.6 & 19.6 & 37.8 & 22.9 \\
\hline
\end{tabular}

The results of table 2 show that for hardwood and softwood, the two-step steam treatment allowed the isolation of a high quality fibre. These fibres showed less resistance to mechanical stress but showed overall better optical properties. Overall, the FIRSST process allowed the production of fibres that could be converted either to pulp or hydrolysed to glucose depending on market potential.

\subsection{Hydrolysis of the cellulose}

The cellulosic hydrolysis yields obtained were 96,83 and $88 \%$, and the average glucose concentration was $10 \mathrm{~g} / \mathrm{L}$. These yields can be maximized by changing some parameters, proven by laboratory tests realised to optimise cellulosic hydrolysis. 


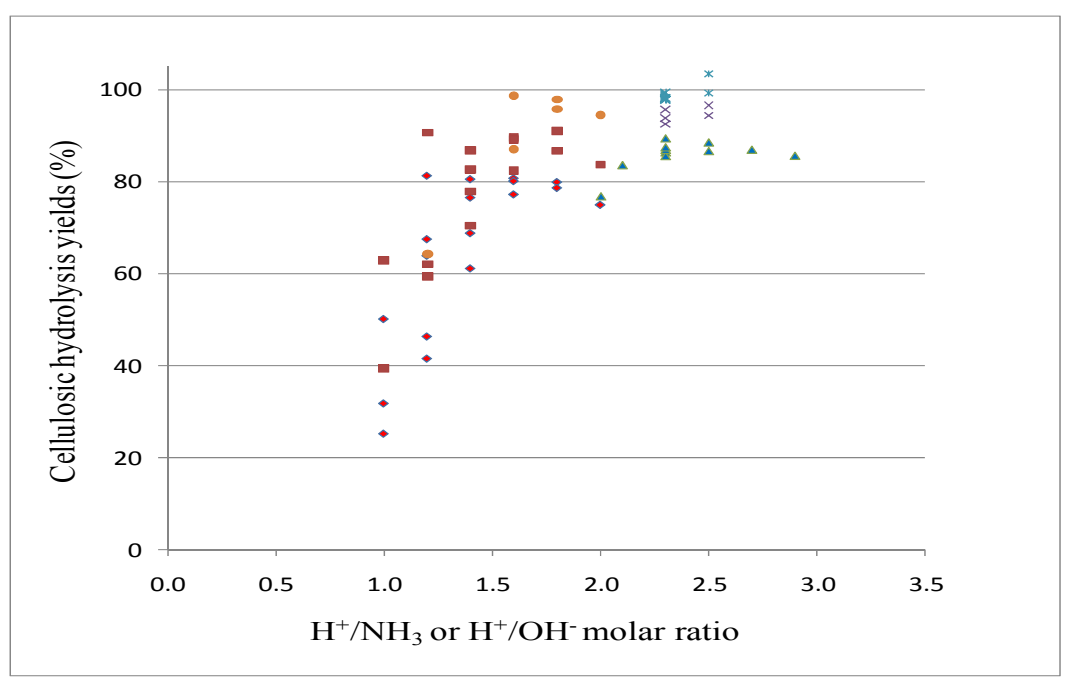

Figure 2: $\quad$ Cellulosic hydrolysis yield versus $\mathrm{H}^{+} / \mathrm{OH}^{-}$or $\mathrm{H}^{+/} \mathrm{NH}_{3}$ molar ratio.

\subsection{Purification of the cellulosic hydrolysate}

Purification of the mixed hydrolysate by electrodialysis leaded to a solution composed of $4.3 \mathrm{~g} / \mathrm{L}$ sodium sulphate and $1.9 \mathrm{~g} / \mathrm{L}$ sulphuric acid with glucose. The separation concentrates the glucose solution by a factor of 4.7 . With the use of AMV and CMV Selemion membranes (Asahi Glass), it is possible to keep around $95 \%$ of the glucose in the diluate. The presence of glucose did not seem to foul the membranes over the time duration of the preliminary process design steps.

Figure 3 presents the composition in sulphuric acid and sodium sulphate of the different compartments versus time:

Due to the voltage increase caused by high ionic concentration in the concentrate (223 g/L sodium sulphate and $126 \mathrm{~g} / \mathrm{L}$ sulphuric acid)-which means a depletion of the ionic content in the diluate-, the solution in the compartment was replaced by a $50 \mathrm{~g} / \mathrm{L}$ sodium sulphate solution after $5.7 \mathrm{~h}$ of purification.

The energy demand was calculated to $0.57 \mathrm{kWh} / \mathrm{kg}$ of separated ions, corresponding to $26 \mathrm{kWh} / \mathrm{kg}$ of glucose recovered. Another purification by electrodialysis was realised with a solution containing ammonium sulphate instead of sodium sulphate. This purification had an energy demand of $0.52 \mathrm{kWh} / \mathrm{kg}$ of separated ions, corresponding to $24 \mathrm{kWh} / \mathrm{kg}$ of glucose. $90 \%$ current efficiency was calculated for the test with sodium sulphate and $92 \%$ with ammonium sulphate. Since the electrical demand is too high translating into an excessive energy cost per $\mathrm{kg}$ of glucose, separation of the ions will have to be done by a combination of less energy intensive steps followed by a final electrodialysis step. 


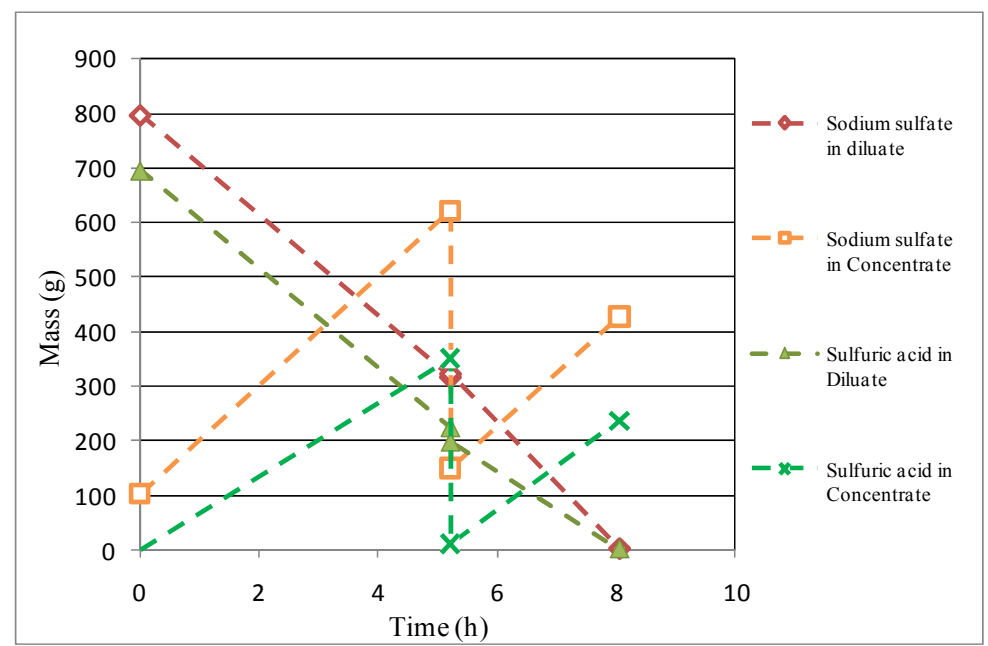

Figure 3: Composition of the diluate and of the concentrate vs. time for the electrodialysis purification.

\subsection{Fermentation of cellulosic sugars}

$2 \mathrm{ml}$ of the fermentation medium were withdrawn after 2, 22 and 44 hours in order to be analysed for ethanol and glucose content, as well and acetic and lactic acid content. The results shown are the mean of duplicates. The progress of the alcoholic fermentation is shown in fig. 4 .

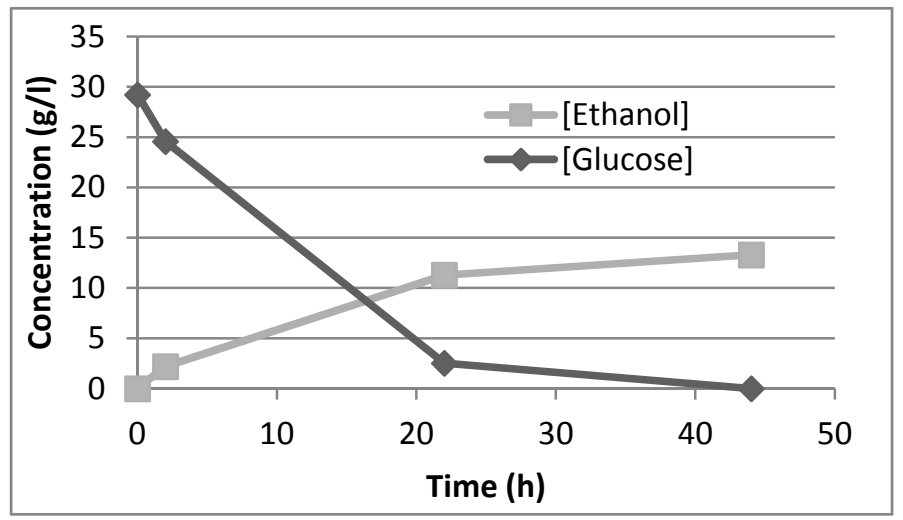

Figure 4: Alcoholic fermentation progress of Ethanol Red Saccharomyces cerevisiae yeasts in lignocellulosic sugars medium.

Yields of $.46 \mathrm{~g} / \mathrm{g}$, an efficiency of $90.1 \%$ and a consumption of $100 \%$ of the glucose were achieved after 44 hours. No methanol was produced during 
the fermentation (data not shown). Inhibitors such as acetic acid and lactic acid were also quantified. Table 3 shows the inhibitor composition of the medium through the fermentation.

Table 3: Major fermentation inhibitor concentration through an alcoholic fermentation by Ethanol Red Saccharomyces cerevisiae yeasts.

\begin{tabular}{ccc}
\hline Time $(\mathrm{h})$ & [lactic acid] $\mathrm{mg} / \mathrm{l}$ & [acetic acid] $\mathrm{mg} / \mathrm{l}$ \\
0 & $<100$ & $<100$ \\
2 & $<100$ & $<100$ \\
22 & $<100$ & 501.0 \\
44 & $<100$ & 503.6 \\
\hline
\end{tabular}

Table 3 shows an increase in acetic acid concentration after 22 hours as a byproduct of the yeast growth. An acetic acid concentration of $.05 \%(\mathrm{w} / \mathrm{v})$ is considered to have no influence on the yeast growth [11]. The results show that no major inhibitor is in a sufficient concentration to inhibit the yeast fermentation throughout the whole process.

\section{Conclusion}

The Feedstock Impregnation Rapid and Sequential Steam Treatment (FIRRST) was shown to be suitable not only for the isolation of the cellulosic matrix but also to produce a high quality pulp that could have a potential for paper production. Results have shown that cellulose can be hydrolysed at $90 \%+$ using a strong ionic solution and that this solution could be purified using membrane technologies. Following treatments, the residual glucose solution can easily be fermented with common yeasts to produce cellulosic ethanol. Key for the economics of this approach will be to optimise the energy consumption for the separation process and recovery of ions.

\section{References}

[1] Damartzis, T. \& Zabaniotou, A., Thermochemical conversion of biomass to second generation biofuels through integrated process design - A review. Renewable \& Sustainable Energy Reviews, 15(1), pp. 366-378, 2011.

[2] Brethauer, S. \& Wyman, C.E., Review: Continuous hydrolysis and fermentation for cellulosic ethanol production. Bioresource Technology, 101(13), pp. 4862-4874, 2010.

[3] Datta, R., Basu, R., Grethlein, H.E., Baker, R.W. \& Huang, Y., Ethanol recovery process and apparatus for biological conversion of syngas components to liquid products. PCT Int. Appl. WO 2009108503 A1 20090903, 2009. 
[4] Zhu, J.Y., Pan, X. \& Zalesny, R.S., Pretreatment of woody biomass for biofuel production: energy efficiency, technologies, and recalcitrance. Applied Microbiology and Biotechnology, 87(3), pp. 847-857, 2010.

[5] Dashtban, M., Maki, M., Leung, K.T., Mao, C. \& Qin, W., Cellulase activities in biomass conversion: measurement methods and comparison. Critical Reviews in Biotechnology, 30(4), pp. 302-309, 2010.

[6] Lavoie, J.-M., Capek, E., Gauvin, H. \& Chornet, E., Production of pulp from Salix viminalis energy crops using the FIRSST process. Bioresource Technology, 101(13), pp. 4940-4946, 2010.

[7] Lavoie, J.-M., Capek, E., Gauvin, H. \& Chornet, E., Production of quality pulp from mixed softwood chips as one of the added value product using the FIRSST process in a general biorefinery concept. Industrial and Engineering Chemistry Research, 49(5), pp. 2503-2509, 2010.

[8] Chornet, E., Chornet, M. \& Lavoie, J.-M., Conversion of cellulosic biomass to sugar. US Provisional Patent Application 80685-2 filed Oct 8, 2008.

[9] ASTM International, Standard test method for determination of carbohydrates in biomass by high performance liquid chromatography. 2008, Annual book of ASTM standards, pp. 1113-1117, 2007.

[10] HACH, Modèle DR2500, Spectrophotomètre de laboratoire, Procédures, Sulfate, Méthode 8051, pp. 1-7, 2002.

[11] Narendranath, N.V., Thomas, K.C. \& Ingledew, W.M., Effects of acetic acid and lactic acid on the growth of Saccharomyces cerevisiae in a minimal medium. Journal of Industrial Microbiology and Biotechnology, 26(3), pp. 171-177, 2001. 